\title{
ELITES LOCAIS DE CIÊNCIA E TECNOLOGIA NO BRASIL: O CASO DO PARQTEC DE SÃO CARLOS (SP)*
}

\author{
Thales Novaes de Andrade e \\ Maurilio de Jesus Silva Filho
}

Neste artigo, tratamos da formação de elites locais de Ciência e Tecnologia (C\&T) no país. Nossa contribuição foi motivada por termos percebido que a ciência política e a sociologia do conhecimento têm dado pouca atenção ao tema da C\&T. Assim, este assunto será abordado valendo-se da literatura nacional e internacional existente, para enfim analisarmos o caso do ParqTec de São Carlos (SP).

A produção tecnológica sofre dia a dia efeitos das transformações internacionais em termos de reorganizações institucionais e alterações do financiamento e desenvolvimento de políticas de inovação. Os grupos que comandam as atividades de inovação tecnológica têm convergido em escala mundial, impondo assim novas fórmulas de cooperação e financiamento.

A globalização e a internacionalização do campo científico e tecnológico representam tendências que têm afetado fortemente a constituição dos grupos sociais que conduzem

\footnotetext{
* O presente artigo traz resultados de pesquisa do projeto 470199/2011-3, financiado pelo CNPq.
} 
a prática tecnológica em âmbito mundial. Hoje é possível detectar processos globais de articulação de empresas, laboratórios e instituições públicas de pesquisa produzindo tecnologias desenraizadas do seu contexto local (cf. Gingras, 2002; Vessuri, 2008; Whitley, 2006).

A maior parte da literatura nacional tem se interessado em analisar as tendências recentes do Estado brasileiro em se adequar às novas regras de financiamento do setor com a globalização e formação de sistemas nacionais de inovação.

E no cenário local? Esse quadro se repete de forma mecânica? Verificam-se as mesmas tendências no cenário de cidades médias, por exemplo?

No contexto europeu, diversos países têm feito esforços consideráveis para descentralizar políticas de C\&T e atrelá-las ao quadro regional. Isso tem propiciado maior autonomia para localidades específicas formularem suas próprias articulações dentro da temática de C\&T (cf. Silva, $2962000)$.

Dessa forma, é preciso analisar como as elites científicas locais estão definindo diretrizes para formular e implementar ações na área científica e tecnológica. A relação com empresas locais, parques tecnológicos e universidades faz com que sejam buscadas interações diferentes daquelas que se dão nas esferas nacionais e estaduais.

Em termos metodológicos, optamos pelo estudo de caso da Fundação Parque de Alta Tecnologia de São Carlos (ParqTec), por ser uma experiência destacada de desenvolvimento tecnológico regional, que tem lugar junto a importantes instituições de ensino e pesquisa, como USP (Universidade de São Paulo) e UFSCar (Universidade Federal de São Carlos), e a Embrapa (Empresa Brasileira de Pesquisa Agropecuária) (cf. Torkomian, 1996). Portanto, é a partir da análise do caso do ParqTec que temos verificado como se dão as articulações entre seus grupos dirigentes e essas instituições. 
Tais informações nos levaram a detectar as tendências de fortalecimento de determinadas áreas e grupos de interesse de instituições tecnológicas internacionais, bem como as aproximações e distanciamentos entre práticas científicas e tecnológicas desses diferentes agentes.

\section{Elites tecnológicas mundiais}

Até a década de 1970, os grupos tecnologicamente dominantes atuavam basicamente na esfera nacional. Havia diferentes modelos de atividade tecnológica como o alemão, inglês, norte-americano e japonês, e os atores relevantes na difusão e manutenção desses modelos eram essencialmente nacionais (cf. Whitley, 2006).

A partir dos anos de 1980, os sistemas nacionais de inovação passam a interagir de forma desterritorializada e flexível, e a intervenção desses grupos se amplia consideravelmente, adquirindo um escopo ainda mais amplo e descentralizado (cf. Humbert, 2005).

Foram sendo estabelecidas redes que cruzam as fronteiras nacionais, compartilhando conhecimentos e formas de atuação (cf. Noble, 1987).

Esses grupos tecnológicos começaram a adotar uma articulação cada vez mais sinérgica e complementar, estabelecendo um diálogo mais próximo e eficiente entre centros produtores e consumidores de tecnologia. Essa diferenciação inclusive deixou de ser tão nítida, pois produtores e consumidores acabaram por se articular em termos de um crescente compartilhamento de conhecimento tecnológico devido ao comportamento reticular das grandes companhias (Andrade, 2011, p. 289).

Grandes empresas modificaram seus padrões de atuação, deslocando atividades importantes para firmas situadas em países periféricos, como constata Humbert (2005, p. 275): 
Muitos autores enfatizavam que as multinacionais estavam transferindo tecnologias obsoletas ou tecnologias muito atrás da fronteira tecnológica e que a transferência não era completa e geralmente era superfaturada. A globalização da tecnologia abriu as "caixas": as tecnologias são cada vez menos adaptadas a um contexto único e as multinacionais não relutam mais em conduzir a P\&D [Produção e Desenvolvimento] no exterior, não apenas em países industrializados, mas também em países menos desenvolvidos [...] graças também à descentralização permitida pelo desenvolvimento das TICs [Tecnologias da Informação e Comunicação].

As elites de engenheiros nas principais áreas industriais passou a se articular com os grandes grupos de empresas transnacionais. Essas elites se mobilizaram para reformular práticas de gerenciamento e produção de novas tecnologias. 298 Andrade (2011) observa que essa tendência levou a uma hierarquização de funções, e as formas de comunicação intersetorial foram também estabelecidas mediante a padronização de procedimentos e a monopolização de conhecimentos técnicos e de ferramentas administrativas, realizadas por engenheiros bem situados nos conglomerados norte-americanos.

Segundo Garcia e Martins (2009), essa tendência foi se configurando na passagem do século XIX para início do século XX, institucionalizando uma relação universidade-empresa que fortaleceu as elites tecnológicas influentes e autônomas. Para ele, é marcante o caso do Massachusetts Institute of Technology.

Nos EUA, o grande precursor de tal movimento foi o Massachusetts Institute of Technology (MIT). Em seu percurso em direção à empresarialização, foi claramente projetado um futuro no qual a academia e a indústria 
caminhariam juntas. Fundado em 1862, o MIT foi concebido para formar líderes destinados a altos cargos na indústria, mais do que pesquisadores universitários, tendo ainda como objetivo produzir o tipo de inovação em larga escala que daria origem, na região de Boston, às indústrias totalmente novas, baseadas em tecnologias emergentes. Vendo-se a si próprio como dedicado ao serviço público, o MIT o entendeu como apoio à economia do país. A forma encontrada para cumprir sua vocação foi a transferência de resultados e descobertas científicas para o setor empresarial privado (Garcia e Martins, 2009, p. 88).

O distanciamento entre laboratórios de pesquisa e universidades tem sido apontado por outros autores. No caso dos Estados Unidos, sua produção industrial, atualmente, é formulada com grande autonomia em relação às elites acadêmicas universitárias (cf. Whitley, 2006). O controle de cientistas sobre pesquisas tecnológicas desenvolvidas nas indústrias tem diminuído sensivelmente, levando a uma autonomização de interesses dos grupos privados.

Trilling (1979) detecta que, a partir dos anos de 1960, há uma radicalização nesse processo, com as elites tecnológicas norte-americanas afastando-se cada vez mais do setor público, o contrário do que ocorre no cenário europeu, cuja tendência é de ênfase em parcerias entre setores governamentais e empresas, em que os interesses dos primeiros possuem um papel preponderante sobre as demandas do setor privado.

Os diversos departamentos e agências do governo francês desempenham um importante papel na formação e estímulo de investimento em novas tecnologias. Ao assumir tal tarefa, eles se dedicam fortemente em fornecer assessoramento e qualificações administrativas para as elites situadas nas grands écoles. Seus membros têm sido treinados 
a pensar a si próprios como agentes selecionados para a continuidade do interesse nacional. Apesar de não serem alinhados aos "interesses especiais", geralmente eles os entendem como relacionados ao seu papel de selecionar determinada companhia (pública ou privada) ou grupo de companhias como instrumento de política nacional (Trilling, 1979, p. 241; tradução livre) ${ }^{1}$.

Andrade (2011, p. 286) acrescenta:

Nos Estados Unidos, esses membros das elites tecnológicas são recrutadas em empresas e laboratórios industriais privados, inexistindo uma escola que agregue e guie suas iniciativas. A liderança de agências estatais ocorria em períodos limitados de tempo por conta do estabelecimento de projetos específicos, especialmente na área militar ou espacial.

A elevação dos níveis de escolarização em diferentes países, as disputas corporativas na área tecnológica e a concorrência em escala mundial propiciaram condições para o surgimento de grupos dominantes na área de tecnologia em diferentes centros (cf. Trilling, 1979).

A literatura que lida com internacionalização de $\mathrm{P} \& \mathrm{D}$ detecta a existência de interesses comuns compartilhados pelos setores que atuam na área de alta tecnologia. Feitas essas considerações, vejamos como se dá a conformação das elites de C\&T no Brasil.

\footnotetext{
1 "The various departments and agencies of the French government play an important role in the initiation and stimulation of investment in new technology. In carrying out that task, they rely heavily on the advice and on the administrative skills of the elite of the grands écoles. Its members have been trained to think of themselves as the chosen agents of the continuing national interest. Although they are not sympathetic with "special interests" generally they see it as consistent with their role to select a particular private or public company or group of companies as the instrument of national policy".
} 


\section{Elites científicas e tecnológicas no Brasil}

Durante as décadas de 1950 a 1970, o desenvolvimento científico e tecnológico dos países latino-americanos foi incorporado na agenda política formal, mas teve poucos efeitos reais em termos de autonomia e consolidação de projetos nacionais efetivos.

A perspectiva nacional-desenvolvimentista foi marcante na trajetória do setor estatal de C\&T. Desde a década de 1950 até o período militar, prevalecia nos cenários político e científico a perspectiva de construção do "Brasil potência", com o Estado sendo o principal agente implementador de todos os grandes projetos científicos e tecnológicos; a burguesia nacional não era vista como um parceiro efetivo. As parcerias feitas na área de C\&T tinham caráter basicamente intraestatal, sem articulações significativas com o setor privado nacional e internacional (cf. Baumgarten, 2008).

Segundo Vessuri (2008), o tema da modernização foi uma meta coletiva recorrente, e diversos países latino-americanos estabeleceram-na como ideia central nos seus processos políticos. Porém, a capacidade da comunidade de pesquisa de alavancar um processo autossustentado de crescimento foi insuficiente. Para esse autor, a entrada nos anos de 1990 mostra que a falta de pujança do setor privado e o endividamento contínuo dos governos nacionais inviabilizaram a expansão dos grupos de pesquisa em áreas estratégicas. As elites acadêmicas da América Latina estavam ainda muito atreladas aos aparelhos estatais e às políticas públicas de C\&T com feições corporativas e autocentradas, sem dinamismo e capacidade de agenda efetiva.

No Brasil, a política de C\&T foi tradicionalmente comandada pela comunidade de pesquisa das universidades públicas e dos centros de pesquisa estatais. Grupos situados em posições de destaque nessa comunidade desfrutam até hoje de uma condição favorável para o estabelecimento dos rumos da C\&T no país (cf. Hey, 2012). Esse controle da comunidade 
de pesquisa sobre a política nacional de C\&T se fez valer muitas vezes de prerrogativas e interesses corporativos, visando à autopreservação de determinados grupos e correntes disciplinares bem instaladas nas principais instituições científicas e universitárias (cf. Dagnino, 2007; Hey, 2012).

Em virtude da crise orçamentária do Estado a partir dos anos de 1980, das novas formas de financiamento da pesquisa, e em consonância com tendências internacionais, nas últimas décadas a área tecnológica no Brasil tem passado por um processo de contínua autonomização em relação aos setores acadêmicos e científicos (cf. Dias, 2012). Um dos aspectos dessas alterações refere-se à necessidade de adoção de uma agenda de inovação, que não teve importância na política científica e tecnológica até os anos de 1990. A partir de então, ocorreu grande transformação das atividades de inovação tecnológica, com a formulação de políticas integradas, abarcando setores produtivos, centros de pesquisa 302 tecnológica e o próprio Estado.

Essas instituições tiveram, nas últimas décadas, uma redefinição importante, procurando sintonizar o país com aquilo que se praticava nas economias avançadas. A criação dos fundos setoriais para financiamento de pesquisas, o advento da Lei de Inovação Tecnológica (Lei federal $\left.\mathrm{n}^{\mathrm{o}} 10.973 / 2004\right)$, a constatação da importância das incubadoras de empresas e a consolidação dos parques tecnológicos mostram a tendência de se integrarem experiências e práticas de inovação tecnológica (cf. Lemos, 2000; Dias, 2012). Apesar de trazerem importantes benefícios para diferentes áreas, tais iniciativas levaram a uma clivagem significativa, privilegiando setores tecnológicos de ponta e, consequentemente, retirando financiamento de centros de pesquisa propriamente científica (cf. Baumgarten, 2008).

Com isso, os critérios de viabilidade tecnológica e de sinergia com empresas tornam-se cada vez mais importantes na alocação de recursos, disponibilização de bolsas e forma- 
ção de mão de obra qualificada. O científico e o tecnológico sem dúvida coexistem, mas os parâmetros de viabilidade técnica e os parâmetros de avaliação são estabelecidos por elites acadêmicas claramente sintonizadas com áreas tecnológicas de ponta e com as formas internacionais de produção do conhecimento.

A Lei de Inovação Tecnológica brasileira, elaborada com base na experiência francesa, se orienta para alguns fins específicos: criação de ambiente para parcerias entre universidades, institutos tecnológicos e empresas, estímulo à participação de instituições de C\&T no processo de inovação e incentivo às inovações dentro das empresas. Objetiva também viabilizar a presença de empresas no espaço público, com compartilhamento de infraestrutura e recursos humanos, públicos e privados, para a pesquisa tecnológica. E, por último, um item mais polêmico: ela normatiza as condições para que pesquisadores de instituições públicas de pesquisa desenvolvam projetos tecnológicos, com oferecimento de bolsas para inovação e o pagamento de adicional à remuneração, além de licença para abertura de empresa tecnológica (cf. Dias, 2012).

A integração de sistemas de inovação, o desenvolvimento de metodologias de avaliação tecnológica e o fortalecimento de uma administração científica nas academias e instituições de pesquisa significam um novo quadro social e gerencial de articulação das atividades inovativas, caminhando para maior privatização das atividades de C\&T e fortalecimento dessas elites internacionalizadas.

\section{O caso do ParqTec de São Carlos}

A Fundação Parque de Alta Tecnologia de São Carlos (ParqTec) foi instituída pelo Conselho Nacional de Desenvolvimento Científico e Tecnológico (CNPq), em 17 de dezembro de 1984, como uma instituição pública de direito privado e sem fins lucrativos, tendo como finalidade pro- 
mover o desenvolvimento regional, otimizando os custos de inovação tecnológica e valorizando o empreendedorismo, agindo, por fim, como gestora desse arranjo organizacional. As áreas principais de atuação das empresas que vieram a ser vinculadas ao ParqTec são as TICs, tais como: novos materiais, instrumentação eletrônica, automação \& robótica, química fina e óptica. Grande parte dessas empresas nasceram da relação com as universidades e/ou dentro delas (cf. Torkomian, 2006).

São Carlos, município do estado de São Paulo, é conhecido hoje como a "Capital da Tecnologia". Tal título muito se deve à implantação na cidade, em meados dos anos de 1980 e seguintes, de incubadoras de empresas de base tecnológica, além, claro, das instituições de pesquisa e de ensino superior nela já existentes. Essa relação com a C\&T, na verdade, remonta a uma história mais antiga, à da criação das universidades estadual e federal no município.

304 Em 1953 é inaugurada a Escola de Engenharia de São Carlos (EESC), vinculada à Universidade de São Paulo (USP). Anos depois, ela se desmembra em mais dois institutos. Surge então, em 1971, o Instituto de Química e Física de São Carlos (IFQSC) e o Instituto de Ciências Matemáticas de São Carlos (ICMSC). No mesmo período, anos de 1970, iniciam-se os trabalhos da recém-criada Universidade Federal de São Carlos (UFSCar), fundada em 1960 e regulamentada apenas em 1968, abrigando à época os cursos de engenharia de materiais e licenciatura em ciências (cf. Torkomian, 1996, p. 34). Mais tarde, em 1994, o IFQSC se desdobra em outros dois institutos: o Instituto de Física de São Carlos (IFSC) e o Instituto de Química de São Carlos (IQSC). Tal histórico nos ajuda a melhor visualizar as condições institucionais que estavam presentes e que, certamente, influenciaram os caminhos traçados pelas políticas de inovação que tomaram forma na figura institucional da Fundação ParqTec. 
A origem do ParqTec está diretamente ligada à difusão na Europa e nos Estados Unidos do que se convencionou chamar de "incubadoras" - associações que têm por objetivo prover os meios de desenvolvimento de empresas de pequeno porte e com viés tecnológico, ajudando em sua estruturação, assim como incentivar os pós-graduandos a transformarem suas ideias em projetos efetivos de criação e produção de produtos e serviços de alta tecnologia.

São Carlos foi uma das primeiras experiências no Brasil de implantação dessa política organizacional, com o ParqTec, seguida posteriormente por outras experiências decorrentes da criação da Associação Nacional de Entidades Promotoras de Empreendimentos de Tecnologias Avançadas (Anprotec) em 1987. Tais medidas vieram ao encontro do que menciona Passador (2003, p. 6): “em cenário comercial globalizado, inovação tecnológica e competitividade econômica são estratégicas para o desenvolvimento. As incubadoras de empresas, neste sentido, surgem como um dos modelos de fomento tecnológico importantes".

O ParqTec constituiu-se, em sua origem, pelo empenho e dedicação de algumas pessoas vinculadas aos principais institutos e universidades de São Carlos e região. Tais empreendedores, no entanto, estavam envolvidos em disputas políticas, cujos aliados os favoreciam e apoiavam na implantação de novos projetos. Era, portanto, um momento de disputas internas no campo científico e tecnológico da cidade. A iniciativa se deu por parte de certos setores científicos, agentes vinculados, na época, ao IFQSC da USP, como os professores Milton Ferreira de Souza e Sylvio Goulart Rosa Jr., e com o apoio fundamental do CNPq, especialmente do seu então presidente, professor Linaldo Albuquerque.

Essa nova instituição veio exatamente para estreitar os laços entre o conhecimento produzido na academia e as possibilidades econômicas que a inovação tecnológica poderia 
eventualmente proporcionar. Mas não foi um processo isento de disputas. Conforme depoimento do professor Sylvio Goulart, houve apoios e obstáculos à sua concretização.

O fundamental dessa história foi o espírito aguerrido da Fundação. Foi parida e colocada na soleira da porta e disseram: se vire, faça a sua função. De fato, o apoio institucional local, que era da USP, foi perdido porque o Linaldo saiu do CNPq e o Milton foi sucedido no Instituto de Física por um adversário da ideia, Foi um período muito difícil (Nosella e Buffa, 2003, p. 57).

Os adversários da proposta do parque tecnológico argumentavam que seria uma forma de burlar o sistema de dedicação exclusiva e levaria os cientistas a se tornarem empreendedores aproveitando-se dos recursos públicos de pesquisa. Ainda segundo esse professor, "o problema do tempo inte306 gral sempre foi o cerne da polêmica. O tempo integral dava bons salários, mas exigia também o compromisso. Eles não queriam abrir mão, em caso nenhum, nem mesmo queriam estudar alguma possibilidade” (Nosella e Buffa, 2003, p. 597).

Nos anos de 1980 e 1990, a criação do ParqTec representava um forte embate no interior do campo acadêmico, mobilizando agentes possuidores de capitais distintos. Enquanto os físicos, detentores de um capital científico forte e capazes de interações para além da universidade, estabeleciam alianças com agências de fomento e poder local, outros setores ficavam mais próximos das diretrizes acadêmicas consolidadas e distantes do empreendedorismo.

Segundo Bourdieu (2004b), o campo científico se modifica a partir da distribuição diversa e desigual das possibilidades dos agentes em fazerem valer suas intenções e prerrogativas. Esses embates que se estabeleceram em São Carlos nos anos de 1980/90 mostram que certas vanguardas científicas procuravam trazer para o Brasil formas 
organizacionais norte-americanas, no momento em que as políticas efetivas de inovação ainda eram novidade no país e não seduziam boa parte dos membros do campo, principalmente aqueles menos sintonizados com o nascente empreendedorismo científico e tecnológico europeu e norte-americano.

O Brasil se encontrava em lento processo de abertura para o mercado mundial, com suas instabilidades políticas decorrentes do estágio ainda prematuro de redemocratização e estabilização das diretrizes de ação e políticas governamentais, demonstrando que "o gosto pela C\&T no Brasil, se existe, é muito recente" (Azevedo, 1996, p. 3).

É somente a partir dos anos de 1990 que os setores privados iniciam um interesse intermitente por inovações tecnológicas em certas áreas de atuação, e determinados agentes locais começam a atuar mais sistematicamente em C\&T. É nesse momento que surgem as primeiras secretarias municipais de C\&T, acompanhando um movimento internacional. Cidades de diferentes regiões, como Vitória, no Espírito Santo, Londrina, no Paraná, Campinas e São Carlos, em São Paulo, dentre outras, estruturaram órgãos voltados para o estabelecimento de uma agenda própria para C\&T, articulados com empresas de base tecnológica, polos tecnológicos e instituições de ensino superior e pesquisa.

O caso de Vitória é paradigmático nesse sentido. Foi lá que emergiu o primeiro sistema municipal de C\&T do país. O prefeito Vitor Buaiz (1989-1992), do Partido dos Trabalhadores (PT), foi quem implantou esse sistema pioneiro. A Lei municipal $n^{\circ} 3.763$ e o Decreto $n^{\circ} 8.741 / 91$ definiram a implantação e normatização dessa política (cf. Godinho e Ferraciolli, 2006).

No caso de São Carlos, o ParqTec pode ser considerado a consolidação das relações entre universidade, Estado e empresa, cujo projeto coletivo de desenvolvimento de inovações tecnológicas para o mercado brasileiro contribui 
para maior autonomia na solução de problemas de diversas áreas do mercado de alta tecnologia, do qual o Brasil ainda se encontra em desvantagem em relação aos países da primeira e segunda revoluções industriais. O principal fator apontado por Torkomian (1996, p. 36) do surgimento do ParqTec em São Carlos

[...] foi a existência de uma overdose de ciência durante longo período de tempo. Os departamentos de alto desempenho acadêmico, que durante algumas décadas enviaram seus pesquisadores ao exterior para estudar em centros de excelência e posteriormente formarem seus programas de pós-graduação e pesquisa, foram os responsáveis maiores por esse transbordamento de ciência da academia para a tecnologia do empreendimento industrial.

Contudo, não apenas o desenvolvimento científico da época pode explicar a formação do ParqTec. O jogo de forças científicas e a acumulação prévia de capital em determinadas áreas pioneiras na cidade, como a física, também foi fundamental para que determinados cientistas pudessem estabelecer uma agenda mais efetiva e ousada de interações com o setor produtivo, mais especificamente em áreas de alta rentabilidade, como óptica, por exemplo. Os principais fundadores do ParqTec são oriundos da área de física, área esta que se lançou nesse empreendimento e tem alcançado os melhores resultados tanto acadêmicos como econômicos.

O surgimento do ParqTec se dá, portanto, em um momento de incorporação de dimensões organizacionais já testadas no cenário internacional e capitaneada por agentes científicos de elite, com boa circulação no CNPq e em áreas de alto potencial de interação com setores produtivos. Além disso, os acordos e alianças táticas locais também foram essenciais, como veremos a seguir. 


\section{As elites do ParqTec}

Atualmente a Fundação ParqTec expandiu suas atividades para além das barreiras municipais, dominando o cenário de inovação em toda a região, englobando os trabalhos de seis grandes incubadoras (Centro Incubador de Empresas Tecnológicas - Cinet; Centro Incubador de Empresas de Software - Softnet; Incubadora de Design - Desing INN; Incubadora de Botucatu; Incubadora de Empresas de Leme - IEL; Incubadora De Rio Claro), tendo cada uma delas a responsabilidade de contribuir para a formação de novos projetos e empreendimentos inovadores e que se configurem de base tecnológica. Uma das questões que sobressai quando se observa a formação de grupos locais de C\&T é que muitas vezes predominam os meios informais de interação, sendo comumente esparsos e irregulares os contatos e articulações profissionais.

Dependendo das atividades desenvolvidas nas empresas e das solicitações dos departamentos circundantes, são estabelecidos os contatos e o nível de complexidade das atividades científicas. De acordo com Araújo e Garcia (2013), para a formação de redes de colaboração científica e tecnológica, a ocorrência de contatos e interações cotidianas é uma variável essencial. Analisando o caso do Polo de Alta Tecnologia de Campinas (SP), foi constatado que a formação de grupos se dá muitas vezes por circunstâncias fortuitas e contatos pouco sistematizados.

O estabelecimento de grupos de referência e elites que comandam os altos postos de tecnologia ocorre em meio a situações personalizadas e arbitrárias, não estando submetida a cálculos e sistemas de competências formalizados. Araújo e Garcia (2013, pp. 123-24) afirmam:

[...] os contatos informais são importantes formas de intercâmbio do conhecimento quando o conhecimento envolvido é complexo e possui maior caráter tácito e 
específico. Nesse caso, a dificuldade de codificação do conhecimento envolvido exige que sejam criados mecanismos capazes de difundir entre os agentes conhecimentos tácitos - e os contatos informais são, de fato, uma forma muito importante de transferência desses conhecimentos.

Não é, portanto, possível estabelecer princípios de ordenamento organizacional que expliquem o desenvolvimento local de C\&T e sua relação com os grupos líderes. As elites científicas se estruturam a partir das oportunidades existentes e mediante os mais improváveis e incertos propósitos oriundos das atividades cotidianas. De acordo com essa literatura, a capacitação de empresas e a continuidade dos projetos de colaboração científica são, em boa parte, engendrados em negociações não formalizadas em áreas de pesquisa ou em acertos institucionais, de modo que os altos postos e as práticas 310 de pesquisa e colaboração dependem dos laços prévios.

No caso específico de São Carlos, a presença de diversas instituições científicas também proporcionou espaço para que determinadas áreas científicas assumissem protagonismo local através de contatos informais e vínculos de proximidade herdados das instituições de origem. Segundo a análise de Baptista (2000), que estudou as articulações entre universidades e empresas na cidade:

Os vínculos que estruturam as redes locais são estabelecidos, principalmente, por meio de consultas diretas e contatos interpessoais. A mobilidade dos diversos atores assegura fluxos contínuos de informação entre os meios acadêmico e empresarial, uma vez que se verifica a participação de alunos de graduação e pós-graduação em atividades nas empresas e, ainda, o acúmulo, por professores e pesquisadores, de funções executivas e de pesquisa [...] A amizade, o conhecimento pessoal, o parentesco, a 
vizinhança, a confiança, são variáveis que influenciam significativamente o comportamento dos atores pesquisados na troca de informações e experiências, na resolução de problemas técnicos e tecnológicos e na estruturação de suas redes, tanto pessoais como profissionais.

O fato de São Carlos concentrar universidades e outras atividades científicas sem dúvida viabiliza a formação de redes de colaboração que são fundamentais para as empresas de tecnologia. Mas essa "overdose" de ciência por si só não é fator explicativo, porque os contatos informais muitas vezes fortalecem os laços já dados pelas articulações entre departamentos, laboratórios e empresas, sacralizando a formação de grupos já bem estabelecidos no contexto científico local.

Os vínculos formais são muito pouco representativos no conjunto de elos que configuram as redes pesquisadas e ocorrem, geralmente, quando os contatos informais evoluem para grandes projetos de desenvolvimento de produtos e processos, envolvendo um volume considerável de recursos materiais, humanos e financeiros. De fato, na configuração de suas redes, os atores estudados recorrem a uma variada gama de recursos e fontes de informação, inclusive aos novos meios eletrônicos, entretanto os contatos face to face - no cotidiano, no próprio ambiente de trabalho, em feiras, congressos, entre outros - registram-se, no cômputo geral, como os mais utilizados pelas empresas pesquisadas, principalmente para informações técnicas e tecnológicas. Ressalta-se, nesse sentido, a irredutibilidade dos conhecimentos tácitos, que não podem ser resgatados e codificados na sua essência, ao tempo em que são imprescindíveis aos processos de decodificação e aprendizagem (Baptista, 2000).

De todo modo, ao reunir grande número de pesquisadores, técnicos, empresários e estudantes, que interagem no 
cotidiano da cidade, o polo tecnológico de São Carlos configura-se em um ambiente bastante favorável a empresas de base tecnológica, facilitando a circulação de informações, o processo de aprendizagem e a geração de conhecimentos e de inovações organizacionais, técnicas e tecnológicas.

Mas como isso ocorreu em São Carlos especificamente? $\mathrm{Na}$ fala de Milton Ferreira de Souza, cofundador do ParqTec, há vários relatos interessantes de como teria sido o processo de nascimento e consolidação das incubadoras e da própria Fundação.

Havia, nos anos de 1980, a necessidade de se articular melhor a produção do Instituto de Física da USP-São Carlos (IFSC/USP), altamente produtivo e internacionalizado academicamente, com setores produtivos, como nos apresenta o depoimento do professor Milton Ferreira:

Queria que conhecimentos do Instituto de Física saíssem de lá para fora. Por exemplo, o nosso grupo de óptica era o mais ativo, todos foram meus alunos. Como fazíamos pesquisa em óptica, tínhamos necessidade de lentes, prismas e era necessidade importá-los. Resolvemos fabricá-los e assim criamos a oficina de óptica, que é a melhor do hemisfério sul. Vimos que havia grande possibilidade de ter indústria óptica e no Brasil e começamos a nos motivar com essa ideia (Nosella e Buffa, 2003, p. 133).

Sem dúvida, o bom posicionamento junto à instituição científica (IFSC/USP), acoplado ao excedente de alunos, bolsas e outros recursos acadêmicos ajudou a viabilizar a proposta. E, ainda mais, contou com apoio da prefeitura de São Carlos do período, dos prefeitos Mello e Vadinho, que colaboraram no aluguel do imóvel da Fundação e no repasse de ISS (Imposto sobre Serviços) das empresas conveniadas.

Outra pessoa que merece destaque aqui é o professor Sylvio Goulart, atualmente presidente de honra da 
Fundação. Não por acaso, ele esteve diretamente ligado ao processo de criação e implantação da Fundação e da primeira incubadora de base tecnológica, o Cinet (Centro Incubador de Empresas Tecnológicas). Carioca e físico de formação e atuação, o professor Sylvio Goulart é o protagonista e principal figura quando o assunto é a história, as dificuldades e as conquistas do ParqTec ao longo dos anos.

Toda a sua carreira deu-se como professor do IFSC, tendo acumulado vários cargos de gestão e controle das políticas em que se pautava a Fundação. Orientou inúmeros trabalhos em sua área de atuação, e, para isso e por isso, tornou-se figura de peso no processo de formação de empreendedores. Na fala do professor, podemos perceber a importância que ele dá à relação entre a Fundação e a universidade. Os alunos que melhor se encaixam para obter projetos financiados e apoio no processo de incubamento na Fundação são, nas palavras dele,

[...] geralmente engenheiros recém-formados que está fazendo mestrado ou doutorado ou é professor aposentado, agora há vários deles. O que agora estamos fazendo é uma campanha estimulando aquele aluno que queria se juntar a nós, se preparar para abrir sua empresa aqui, incubar aqui, porque aqui ele terá todo o apoio (Nosella e Buffa, 2003, p. 64).

Tendo em vista a importância que o professor Sylvio Goulart dá aos alunos de graduação e pós-graduação, é de grande valor para este estudo que possamos expor os principais membros e instituições de origem que alimentam esse seleto grupo de inovadores e empreendedores.

\section{A atual configuração das elites locais vinculadas ao ParqTec}

Analisaremos a seguir quais as atuais lideranças marcantes no ParqTec, identificando suas vinculações insti- 
tucionais e acadêmicas, de modo a entender como se dá hoje a montagem dessas elites científicas e tecnológicas da região de São Carlos.

Um levantamento feito junto às empresas sediadas no ParqTec nos possibilitou identificar alguns dos principais sócios-fundadores de empresas que ali nasceram e se desenvolveram, ou, no jargão das incubadoras, que ali se graduaram. Dentre eles, se destacam os professores Jarbas Caiado e Milton Ferreira de Souza (ambos do IFSC/USP), sócios-fundadores da Opto Eletrônica e da Engecer, sendo o professor Milton também sócio-fundador da Cerauto e Inovamat, além de membro do conselho sênior da Federação das Indústrias do Estado de São Paulo (Fiesp) no ano de 1993, e um dos fundadores do ParqTec junto com o professor Sylvio Goulart.

Esse levantamento cruzado com dados coletados da plataforma Lattes do CNPq, gerou os Quadros 1 e 2, relacio314 nando os principais agentes de inovação de São Carlos com ligação direta ou indireta com as incubadoras do ParqTec, sejam eles sócios-fundadores de empresas de base tecnológica ou apenas professores que orientam seus alunos não só na pesquisa acadêmica, mas também na lógica empreendedora da inovação. Essa análise comparativa nos propiciará relacionar tais dados com a variedade de elementos acerca da prática e das especificidades desses agentes apresentados anteriormente.

\section{Quadro 1}

Relação dos professores doutores envolvidos em empresas de base tecnológica em São Carlos

\begin{tabular}{|r|l|}
\hline \multicolumn{2}{|c|}{ Prof. Dr. Sylvio Goulart Rosa Júnior } \\
\hline Vínculo acadêmico/Depto. & Professor aposentado do IFSC/USP \\
\hline Empresa/Instituição & ParqTec - fundador e presidente de honra (1984-atual) \\
\hline Formação acadêmica & $\begin{array}{l}\text { Doutorado em física - University of Wyoming (1972) e pós- } \\
\text { doutorado pela Princeton University (1980), ambas nos EUA }\end{array}$ \\
\hline
\end{tabular}




\begin{tabular}{|c|c|}
\hline \multicolumn{2}{|r|}{ Prof. Dr. Milton Ferreira de Souza } \\
\hline Vínculo acadêmico/Depto. & $\begin{array}{l}\text { Professor emérito e visitante do IFSC/Depto. de Física e } \\
\text { Ciência dos Materiais }\end{array}$ \\
\hline Empresa/Instituição & $\begin{array}{l}\text { Fundador do ParqTec (1984); cofundador das empresas Opto } \\
\text { Eletrônica, Engecer, Cerauto e Inovamat; além de membro do } \\
\text { Conselho da Fiesp (1993) }\end{array}$ \\
\hline Formação acadêmica & $\begin{array}{l}\text { Graduação em química pela Universidade do Rio de Janeiro } \\
\text { (1953) e pós-doutorado em física pela University of Utah } \\
\text { (1971), EUA }\end{array}$ \\
\hline \multicolumn{2}{|c|}{ Prof. Dr. Jarbas Caiado de Castros Neto } \\
\hline Vínculo acadêmico/Depto. & $\begin{array}{l}\text { Professor titular do IFSC/USP/Depto. de Física e Ciência dos } \\
\text { Materiais }\end{array}$ \\
\hline Empresa/Instituição & Sócio-fundador da Opto Eletrônica e da Engecer \\
\hline Formação acadêmica & Doutorado em física pelo MIT (1981), EUA \\
\hline \multicolumn{2}{|r|}{ Prof. Dr. Reginaldo Teixeira Coelho } \\
\hline Vínculo acadêmico/Depto. & $\begin{array}{l}\text { Professor titular da EESC-USP/Depto. de Engenharia de } \\
\text { Produção }\end{array}$ \\
\hline Empresa/Instituição & EESC-USP/Professor titular \\
\hline Formação acadêmica & $\begin{array}{l}\text { Doutorado em engenharia mecânica pela The University } \\
\text { of Birmingham (1995), Inglaterra, e pós-doutorado pela } \\
\text { Mcmaster University Hamilton (2006), Canadá }\end{array}$ \\
\hline \multicolumn{2}{|c|}{ Prof. Dr. João Fernando Gomes de Oliveira } \\
\hline Vínculo acadêmico/Depto. & $\begin{array}{l}\text { Professor titular da EESC-USP/Depto. de Engenharia de } \\
\text { Produção }\end{array}$ \\
\hline Empresa/Instituição & $\begin{array}{l}\text { IPT (2008-2012), Capes (2011-atual), CNPq (2004-2005) e } \\
\text { MCT (2007-atual) além de membro da International Academy } \\
\text { for Production Engineering, CIRP (2005-atual), França }\end{array}$ \\
\hline Formação acadêmica & $\begin{array}{l}\text { Pós-doutorado em engenharia de produção pela University of } \\
\text { California, Berkeley (1994), EUA }\end{array}$ \\
\hline \multicolumn{2}{|r|}{ Prof. Dr. Carlos Alberto Fortulan } \\
\hline Vínculo acadêmico/Depto. & $\begin{array}{l}\text { Professor associado da EESC-USP/Depto. de Engenharia } \\
\text { Mecânica }\end{array}$ \\
\hline Empresa/Instituição & $\begin{array}{l}\text { Passagens pela Cerauto e pela Engecer enquanto era bolsista } \\
\text { com dedicação exclusiva pelo ParqTec (1999-2002) }\end{array}$ \\
\hline Formação acadêmica & $\begin{array}{l}\text { Pós-doutorado em engenharia e ciências dos materiais pela } \\
\text { UFSCar (1998) }\end{array}$ \\
\hline
\end{tabular}

Fonte: Elaboração própria. Base de Dados do CNPq - Plataforma de Curriculum Lattes. 
Observamos no Quadro 1 figuras de importante presença e influência no desenvolvimento das práticas e rumos da inovação não apenas no cenário local, como também em nível estadual e federal. Destacam-se, entre eles, os professores Sylvio Goulart e Milton Ferreira de Souza, ambos parte do processo de fundação do ParqTec.

As trajetórias acadêmicas são diversas. Exceto o professor Carlos Alberto Fortulan, que teve a formação compartilhada entre USP (doutorado) e UFSCar (graduação, mestrado e pós-doutorado), todos os demais professores tiveram alguma experiência internacional em universidades de ponta, destacando-se as áreas de mecânica, produção, óptica e ciências dos materiais.

A passagem por alguma instituição internacional de ensino de ponta solidifica esse grupo distinto de agentes, dando a eles uma dimensão privilegiada de suas respecti316 vas áreas de atuação. Citamos, como exemplo, a passagem do professor Jarbas Caiado pelo MIT (Massachusetts Institute of Technology), instituição permeada pela lógica da inovação e do empreendedorismo.

Sylvio Goulart fez várias viagens à Europa na época da fundação do ParqTec, e foi de lá que trouxe influências e teve inspirações para a implantação das incubadoras aqui. Isso pode explicar a relação tão especial que mantém até os dias de hoje com a instituição, sendo inclusive seu presidente de honra.

No Quadro 2, mostramos o desenvolvimento dos laços institucionais entre as instituições públicas de pesquisa e as empresas de base tecnológica que estão presentes no cenário regional de inovação, do qual São Carlos é o centro. Laços estes que se apresentam e se solidificam nas relações de orientação dos alunos de pós-graduação e seus respectivos professores/orientadores previamente inseridos nessa lógica empreendedora de inovação. 


\section{Quadro 2}

\section{Relação dos pós-graduandos envolvidos nas empresas de base tecnológica de São Carlos}

\begin{tabular}{|c|c|}
\hline \multicolumn{2}{|r|}{ Marcelo Del Guerra } \\
\hline Orientação/Depto. & $\begin{array}{l}\text { Prof. Dr. Reginaldo Teixeira Coelho, EESC-USP/Depto. de Engenharia } \\
\text { de Produção }\end{array}$ \\
\hline Titulação acadêmica & $\begin{array}{l}\text { Doutorado em engenharia de produção mecânica pela EESC-USP, } \\
\text { ênfase em Otimização de Processos de Fabricação (2009) }\end{array}$ \\
\hline Empresa/Função & $\begin{array}{l}\text { Accure Technologies Instrumentos - responsável pela empresa } \\
\text { (2006-atual) }\end{array}$ \\
\hline \multicolumn{2}{|r|}{ Ricardo Arai } \\
\hline Orientação/Depto. & $\begin{array}{l}\text { Prof. Dr. Reginaldo Teixeira Coelho, EESC-USP/Depto. de Engenharia } \\
\text { de Produção }\end{array}$ \\
\hline Titulação acadêmica & $\begin{array}{l}\text { Mestrado em engenharia de produção pelo IFSC/USP, com ênfase } \\
\text { em Processos de Fabricação (2008) }\end{array}$ \\
\hline Empresa/Função & $\begin{array}{l}\text { Accure Technologies Instrumentos - sócio e engenheiro de } \\
\text { manufatura (2006-2012) }\end{array}$ \\
\hline \multicolumn{2}{|r|}{ Fábio Ferraz Júnior } \\
\hline Orientação/Depto. & $\begin{array}{l}\text { Prof. Dr. João Fernando Gomes de Oliveira, EESC-USP/Depto. de } \\
\text { Engenharia de Produção }\end{array}$ \\
\hline Titulação acadêmica & $\begin{array}{l}\text { Doutorado em engenharia mecânica pela EESC-USP/NUMA, com } \\
\text { ênfase em Processos de Fabricação (2008) }\end{array}$ \\
\hline Empresa/Função & $\begin{array}{l}\text { SENSOFT Indústria e Automação Ltda. - diretor e sócio-fundador } \\
\text { (2003-atual) }\end{array}$ \\
\hline \multicolumn{2}{|r|}{ Carlos Magno de Oliveira Valente } \\
\hline Orientação/Depto. & $\begin{array}{l}\text { Prof. Dr. João Fernando Gomes de Oliveira, EESC-USP/Depto. de } \\
\text { Engenharia de Produção }\end{array}$ \\
\hline Titulação acadêmica & $\begin{array}{l}\text { Doutorado em engenharia mecânica pela EESC-USP, com sanduíche } \\
\text { na University of California, Berkeley, EUA (2002) }\end{array}$ \\
\hline Empresa/Função & $\begin{array}{l}\text { SENSOFT Indústria e Automação Ltda. - diretor e sócio-fundador } \\
\text { (2003-atual) }\end{array}$ \\
\hline \multicolumn{2}{|r|}{ Luiz André Melara de Campos Bicudo } \\
\hline Orientação/Depto. & $\begin{array}{l}\text { Prof. Dr. João Fernando Gomes de Oliveira, EESC-USP/Depto. de } \\
\text { Engenharia de Produção }\end{array}$ \\
\hline Titulação acadêmica & $\begin{array}{l}\text { Graduação pela UFSCar e doutorado em engenharia mecânica, com } \\
\text { ênfase em Projetos de Máquinas pela EESC-USP (1997) }\end{array}$ \\
\hline Empresa/Função & $\begin{array}{l}\text { SENSIS São Carlos Indústria e Comércio de Equipamentos } \\
\text { Eletrônicos - sócio-proprietário (1995-atual) }\end{array}$ \\
\hline
\end{tabular}




\section{João Jorge de Faria Gomes}

\begin{tabular}{|c|c|}
\hline Orientação/Depto. & $\begin{array}{l}\text { Prof. Dr. João Fernando Gomes de Oliveira, EESC-USP/Depto. de } \\
\text { Engenharia de Produção }\end{array}$ \\
\hline Titulação acadêmica & $\begin{array}{l}\text { Doutorado em engenharia mecânica pela EESC-USP (2001) e pós- } \\
\text { doc com ênfase em Processos de Produção (2002) }\end{array}$ \\
\hline Empresa/Função & $\begin{array}{l}\text { SENSIS São Carlos Indústria e Comércio de Equipamentos } \\
\text { Eletrônicos - sócio-proprietário (1995-atual) }\end{array}$ \\
\hline \multicolumn{2}{|r|}{ Juarez Felipe Junior } \\
\hline Orientação/Depto. & $\begin{array}{l}\text { Prof. Dr. João Fernando Gomes de Oliveira, EESC-USP/Depto. de } \\
\text { Engenharia de Produção }\end{array}$ \\
\hline Titulação acadêmica & $\begin{array}{l}\text { Mestrado (1992), doutorado (1996) e pós-doc (1997) em } \\
\text { engenharia mecânica pela EESC-USP, com ênfase em Processos de } \\
\text { Produção }\end{array}$ \\
\hline Empresa/Função & $\begin{array}{l}\text { SENSIS São Carlos Indústria e Comércio de Equipamentos } \\
\text { Eletrônicos - sócio-proprietário (1998- atual) }\end{array}$ \\
\hline \multicolumn{2}{|r|}{ Mario Antonio Stefani } \\
\hline Orientação/Depto. & Prof. Dr. Jarbas Caiado, IFSC/USP \\
\hline Titulação acadêmica & Doutorado em física pelo IFSC/USP (1995) \\
\hline Empresa/Função & Opto Eletrônica S.A. - diretor de P\&D (1986-atual) \\
\hline \multicolumn{2}{|r|}{ Fatima Maria Mitsue Yasuoka } \\
\hline Orientação/Depto. & Prof. Dr. Jarbas Caiado, IFSC/USP \\
\hline Titulação acadêmica & $\begin{array}{l}\text { Mestrado (1989), doutorado (1997) e pós-doc em física aplicada à } \\
\text { oftalmologia pelo IFSC/USP (2000) }\end{array}$ \\
\hline Empresa/Função & Opto Eletrônica S.A. - pesquisadora (1992-2013) \\
\hline \multicolumn{2}{|r|}{ Lucimara Cristina Nakata Scaduto } \\
\hline Orientação/Depto. & Prof. Dr. Jarbas Caiado, IFSC/USP \\
\hline Titulação acadêmica & $\begin{array}{l}\text { Doutorado em física (2013), com ênfase em óptica, e com } \\
\text { sanduíche no College of Optical Sciences - University of Arizona, } \\
\text { OSC, EUA }\end{array}$ \\
\hline Empresa/Função & Opto Eletrônica S.A. - pesquisadora (2006-atual) \\
\hline \multicolumn{2}{|r|}{ Tiago Almeida Ortega } \\
\hline Orientação/Depto. & Prof. Dr. Jarbas Caiado, IFSC/USP \\
\hline Titulação acadêmica & $\begin{array}{l}\text { Graduado, mestre e doutorando em física, com ênfase na área de } \\
\text { óptica pelo IFSC/USP }\end{array}$ \\
\hline Empresa/Função & Opto Eletrônica S.A. - pesquisador (2007-atual) \\
\hline
\end{tabular}




\begin{tabular}{|c|c|}
\hline \multicolumn{2}{|r|}{ Diego Lencione } \\
\hline Orientação/Depto. & Prof. Dr. Jarbas Caiado, IFSC/USP \\
\hline Titulação acadêmica & Mestrado em física pelo IFSC/USP, com ênfase na área de óptica \\
\hline Empresa/Função & $\begin{array}{l}\text { Opto Eletrônica S.A. - pesquisador (2008-2012); técnico de nível } \\
\text { superior no IQSC/USP (2012-atual) }\end{array}$ \\
\hline \multicolumn{2}{|r|}{ Luis Alberto Vieira de Carvalho } \\
\hline Orientação/Depto. & Prof. Dr. Jarbas Caiado, IFSC/USP \\
\hline Titulação acadêmica & $\begin{array}{l}\text { Doutorado e pós-doc pelo IFSC/USP na área de física aplicada, } \\
\text { com ênfase em óptica, e com sanduíche na University of California, } \\
\text { Berkeley (EUA) }\end{array}$ \\
\hline Empresa/Função & $\begin{array}{l}\text { WaveTek - Membro-fundador (2007-atual) e pesquisador do IFSCI } \\
\text { USP, no Laboratório de Óptica Oftálmica (2006-atual) }\end{array}$ \\
\hline \multicolumn{2}{|r|}{ Márcio Pereira Borali } \\
\hline Orientação/Depto. & $\begin{array}{l}\text { Prof. Dr. Harry Edmar Schulz, EESC/USP/Depto. de Hidráulica e } \\
\text { Saneamento Básico }\end{array}$ \\
\hline Titulação acadêmica & $\begin{array}{l}\text { Mestrado em engenharia ambiental, com ênfase em resíduos } \\
\text { sólidos }\end{array}$ \\
\hline Empresa/Função & Aliança Orgânica Soluções Ambientais - membro-fundador \\
\hline \multicolumn{2}{|r|}{ José Roberto Garbin } \\
\hline Orientação/Depto. & Prof. Dr. Ladislau Martin Neto, EESC/USP e Embrapa \\
\hline Titulação acadêmica & $\begin{array}{l}\text { Doutorado em ciências e engenharia de materiais pela EESC/-USP, } \\
\text { com ênfase em Física Aplicada à Agricultura e ao Meio Ambiente } \\
\text { (2004) }\end{array}$ \\
\hline Empresa/Função & $\begin{array}{l}\text { Natureza Ativa - sócio-proprietário (2006-atual) e diretor da } \\
\text { Faculdade de Tecnologia (Fatec), Sertãozinho (2009-atual) }\end{array}$ \\
\hline
\end{tabular}

Fonte: Elaboração própria. Base de Dados do CNPq - Plataforma de Curriculum Lattes.

Percebemos, ao analisar o conjunto de dados desses dois quadros, a presença hegemônica de pesquisadores da USP/São Carlos, a maioria deles oriundos do IFSC, berço da iniciativa da qual surgiu o ParqTec. É evidente a sinergia entre fundação e instituição, representada por um seleto grupo de professores e alunos que ali se fazem presentes e que desenvolvem no ParqTec pesquisas iniciadas na universidade. 
Destaca-se, de forma mais que acentuada, a presença do professor Jarbas Caiado de Castro Neto, da empresa Opto Eletrônica: muitos de seus orientandos de pós-graduação, desenvolvedores de pesquisas na área de óptica, alocados no IFSC, têm suas carreiras como pesquisadores atreladas a essa empresa. Assim, o professor Jarbas é um membro possuidor de grande capital científico e tecnológico, de forte influência sobre os rumos da inovação nesse contexto e área de conhecimento, responsável pela formação de mão de obra especializada segundo as demandas de seu empreendimento.

Ao transportar os benefícios da formação dessa mão de obra diferenciada para o seu empreendimento, o professor Jarbas demonstra a íntima relação construída entre empresa e universidade, bem como a direta transferência do conhecimento acadêmico das instituições públicas para sua aplicação no setor empresarial privado, do qual este setor é beneficiário direto.

320 Outro agente decisivo para a política local de inovação e também com presença marcante nesse ambiente é o professor João Fernando Gomes de Oliveira. Docente do Departamento de Engenharia de Produção da EESC/USP e pesquisador $1 \mathrm{~A}$ do $\mathrm{CNPq}$ (maior nível de reconhecimento institucional, que relaciona produtividade e mérito acadêmico), tem inegável destaque na conformação desses grupos tecnológicos e empreendedores.

Entre os anos de 2008 a 2012, o professor João Fernando se licenciou da USP para ocupar o cargo de Diretor Presidente do Instituto de Pesquisas Tecnológicas do Estado de São Paulo (IPT). Nos últimos anos, o IPT implementou medidas de reorganização institucional importantes, sintonizadas com as tendências internacionais de inovação e produção do conhecimento. Várias iniciativas foram tomadas visando à internacionalização do Instituto e sua inserção em modalidades privadas de produção e financiamento (Andrade, Silva e Cepêda, 2012). 
A presença do professor João Fernando à frente do IPT e sua liderança no ParqTec indicam forte convergência nas fórmulas atuais da atividade tecnológica e de inovação pelas elites regionais. Tal sintonia é responsável pela intensa participação do ParqTec em atividades de ponta no cenário regional e estadual. Duas empresas estão diretamente associadas ao professor João Fernando, com vários de seus orientandos de doutoramento trabalhando nelas: a Sensis e a Sensoft, ambas da área de engenharia mecânica e que atuam com sensoriamento e automação, com financiamento de alguns de seus projetos advindos da Fapesp (Fundação de Amparo à Pesquisa do Estado de São Paulo).

A forte articulação entre as empresas, o IPT e a EESC apontam para uma articulação nova do ParqTec, em que a área de engenharia de produção e mecânica passam a dividir proeminência com a física, juntando novos agentes que se fortalecem mutuamente.

O professor Reginaldo Teixeira Coelho é engenheiro mecânico, docente do Departamento de Engenharia de Produção da EESC, pesquisador 1C do CNPq, e ex-orientando do professor João Fernando, do mesmo departamento. Ele aparece como outro agente de grande influência para o desenvolvimento e reprodução das estruturas da inovação local de São Carlos. É membro-fundador da Accure Tecnologies, ligada ao Instituto Fábrica do Milênio, que atua na área de produção de ferramentas de alta precisão para controle dimensional e monitoramento de processos de fabricação. Esse professor também orienta outros agentes vinculados a essa empresa, consolidando-se recentemente como outra importante liderança do ParqTec.

Em sua análise, Torkomian (1996, p. 78) mostra que, na época, os principais tipos de relacionamento existentes entre empresas de alta tecnologia e universidades referiam-se à absorção de tecnologia via contatos informais em 
geral, e também via trabalhos complementares e atuação profissional por meio de cursos, ou mesmo as universidades eram utilizadas para os testes finais dos produtos desenvolvidos pelas empresas.

Esses dados, em sua grande maioria, são frutos da construção de vínculos que os próprios pesquisadores disponibilizam em seus currículos Lattes, constituindo assim uma rede local de pesquisa, inovação e empreendedorismo. Por sua vez, esclarecem a maciça presença de membros da USP, alocados no IFCS e na EESC, envolvidos com a inovação na cidade de São Carlos.

No Brasil, em particular, a formação desses engenheiros e cientistas voltados para a inovação relacionada ao empreendedorismo é uma exclusividade do setor institucionalizado de incentivo às Políticas de Ciência e Tecnologia (PCT), e estão ligados aos grandes centros estatais de pesquisa científica e tecnológica. Tal característica é uma especificidade 322 brasileira, não sendo a regra quando comparamos com iniciativas mais bem consolidadas de outros países e anteriores às do Brasil. Por exemplo, "nos Estados Unidos, ao contrário, esses membros das elites tecnológicas são recrutados junto a empresas privadas e laboratórios industriais privados, inexistindo uma escola que agregue e guie suas iniciativas" (Andrade, 2011, p. 286).

Tal especificidade advinda das políticas de inovação brasileira pode nos ajudar a entender o porquê desses agentes se tornarem um grupo distinto dentro e fora do campo científico, conformando o que Andrade denomina "elites tecnológicas”, que aqui são encontradas em nível local.

O caso do ParqTec nos permite identificar as particularidades do contexto de inovação no nível local, em que a formação de grupos distintivos está relacionada às instituições de ensino e pesquisa às quais esses agentes estão ligados e atuam na manutenção e controle de seus capitais específicos. 
Para Andrade (2011, p. 301), "o científico e o tecnológico sem dúvida coexistem, mas os parâmetros de viabilidade técnica e os parâmetros de avaliação são estabelecidos por elites acadêmicas claramente sintonizadas com áreas tecnológicas de ponta”.

Outra característica que podemos inferir, a partir da análise dos dados colhidos durante a pesquisa, e que demonstra uma centralidade nas práticas de inovação dessa cidade, é que de as instituições de ensino e pesquisa alocadas na USP-São Carlos, como o IFSC e a EESC, são os principais atores envolvidos no processo de criação e incubação de empresas de base tecnológica. Esse fato pode ser sustentado quando observamos os quadros anteriores e constatamos pouca participação da UFSCar nesse contexto, por meio de seus pesquisadores/professores e pela contribuição quase inexistente de seus agentes para as pesquisas em curso no ParqTec.

O controle dos docentes da USP sobre a pesquisa do ParqTec e a entrada de novas áreas de pesquisa apontam para uma tendência de circulação de elites científicas e tecnológicas nesse contexto.

A presença menor de pesquisadores da UFSCar e Embrapa nas atividades do ParqTec atualmente é um dado que permite vislumbrar uma proeminência da informalidade no estabelecimento da agenda científica local.

A percepção de uma elite já estabelecida e outra em processo de ascensão pode ser uma boa forma para pensarmos as dinâmicas que ocorrem em nível local nas políticas de C\&T que envolvem as diferentes instituições e tem a inovação enquanto espaço de disputas e controle do campo.

No nosso caso, no entanto, não podemos dizer que os atores hoje em destaque no controle dos rumos institucionais e dos processos de inovação, a saber, os institutos vinculados à USP, certamente aqui enquadrados enquanto a elite tecnológica de destaque e com o histórico mais bem 
consolidado no tocante à inovação em São Carlos, estejam com sua posição em risco.

Como a forma mais direta de entrada nesse seleto e restrito grupo da inovação é através das parcerias entre os doutorandos e pelas orientações dos professores já estabelecidos enquanto elites, torna-se mais claro entender quais dificuldades outras instituições encontram para adentrar e se posicionar em pé de igualdade nesse ambiente de inovação. Os meios informais de interação e os contatos eventuais e irregulares, podendo ser mais ou menos intensos, são os responsáveis por diversas atividades que ocorrem nas empresas e nas universidades.

Como diria Bourdieu (2004a), o campo científico encontra seus próprios meios de seleção, recrutamento e reprodução do capital relevante e dos seus representantes diretos. No plano local, as formas de posicionamento científico e os meios de crédito tecnológico circulam por méto324 dos pouco científicos ao adotarem fichas restritas a certos ambientes e filiações.

A discussão do caso de São Carlos é especialmente interessante ao que se refere às questões relacionadas ao estabelecimento de agendas locais de C\&T. Se, por um lado, há um conjunto de instituições e práticas governamentais propícias à implementação de políticas bem concatenadas, por outro ainda se faz necessária uma maturação institucional em termos de metas e modelos de formulação de políticas intersetoriais e formação de quadros especializados.

A proeminência de determinados agentes e instituições sem dúvida confere pujança e iniciativa às atividades científicas e tecnológicas, mas o direcionamento é estabelecido localmente de acordo com articulações pouco institucionalizadas e concorrenciais. 
Nossa pesquisa nos aproximou um pouco da realidade existente por trás dos processos de consolidação da base tecnológica de São Carlos e orientou-nos também sobre a importância de conhecer os principais agentes envolvidos no cenário de inovação e empreendedorismo implantado.

Contudo, talvez o que mais tenha deixado marca neste trabalho é a necessidade de saber mais, de pesquisar mais a respeito de como esses agentes se constituem no campo local e como vão se relacionando e trocando experiências e conhecimentos. Sabemos que estamos lidando com um grupo diferenciado de agentes, e que esses agentes possuem meios de manter e replicar suas práticas através das instituições em que atuam.

Certamente outras pesquisas já se lançaram em uma análise para entender as relações locais entre público e privado, ou mesmo entre ciência e mercado. A nossa é uma pequena contribuição

\section{Thales Novaes de Andrade}

é professor do Departamento de Ciências Sociais da Universidade Federal de São Carlos (UFSCar) e bolsista do CNPq.

\section{Maurilio de Jesus Silva Filho}

é mestrando em Antropologia Social na UFSCar.

\section{Bibliografia}

ANDRADE, T. 2011. "As elites tecnológicas". Revista Política Hoje, v. 20, n. 1, pp. 280-309.

ANDRADE, T.; SILVA, L. R.; CEPÊDA, V. A. 2012. "Condição de trabalho de técnicos e pesquisadores nos institutos públicos de pesquisa: o caso do IPT". Liinc em Revista, v. 8, n. 1.

ARAÚJO, V. C.; GARCIA, R. 2013. "Transbordamentos locais de conhecimento por meio de contatos informais: uma análise a partir do sistema local de indústrias TIC de Campinas". Revista Brasileira de Inovação, v. 12, n. 1. 
AZEVEDO, F. A. 1996. "A era do conhecimento, a ciência e tecnologia e o desenvolvimento”. TECBAHIA - Revista Baiana de Tecnologia, v. 11, n. 3, pp. 37-52.

BAPTISTA, R. F. 2000. "Redes de inovação no contexto dos tecnopolos: a experiência de São Carlos, Brasil". Scripta Nova - Revista Electrónica de Geografía y Ciencias Sociales, v. 69, n. 32. Disponível em: <http://www. ub.es/geocrit/sn-69-32.htm>. Acesso em: 30 de jan. 2015.

BAUMGARTEN, M. 2008. Conhecimento e sustentabilidade: políticas da ciência, tecnologia e inovação no Brasil contemporâneo. Porto Alegre: Ed. UFRGS/Sulina.

BOURDIEU, P. 2004a. Os usos sociais da ciência: por uma sociologia clínica do campo científico. São Paulo: Ed. Unesp. 2004b. Para uma sociologia da ciência. Lisboa: Edições 70.

DIAS, R. B. 2012. Sessenta anos de política científica e tecnológica no Brasil. Campinas: Ed. Unicamp.

GARCIA, J. L.; MARTINS, H. 2009. "O ethos da ciência e suas transformações contemporâneas, com especial atenção à biotecnologia”. ScienticeStudia, São Paulo, v. 7, n. 1.

GINGRAS, Y. 2002. "Les formes spécifiques de l'internationalité du champ scientifique”. Actes de la Recherche en Sciences Sociales, n. 141-142,

326 pp. $31-45$.

GODINHO, M.J.; FERRACIOLLI, L. 2006. "Soluções mundialmente aplicáveis: iniciativas locais em educação em ciência e tecnologia de Vitória, Espírito Santo - Brasil”. In: XII IOSTE SYMPOSIUM, Malasia.

HEY, A. P. 2012. "Elites científicas: o caso da Academia Brasileira de Ciências”. In: $36^{\circ}$ ENCONTRO ANUAL DA ANPOCS, Águas de Lindoia.

HUMBERT, M. 2005. "Globalização e glocalização: problemas para países em desenvolvimento e implicações para políticas supranacionais, nacionais e subnacionais". In: LASTRES, H. et al. (orgs.). Conhecimento, sistemas de inovação e desenvolvimento. Rio de Janeiro: UFRJ.

LEMOS, C. 2000. "Inovação na era do conhecimento". Parcerias Estratégicas, n. 8, pp.157-79.

NOBLE, D. 1987. El diseño de Estados Unidos: La ciencia, la tecnología y la aparición del capitalismo monopolístico. Madrid: Ministerio del trabajo y seguridad social.

NOSELLA, P.; BUFFA, E. 2003. O parque de alta tecnologia de São Carlos. São Carlos, SP: EdUFScar.

PASSADOR, J. L. 2003. "Política pública em ciência e tecnologia: as redes de fomento tecnológico e as relações entre governo, empresas 
e universidade”. In: VIII CONGRESO INTERNACIONAL DEL CLAD SOBRE LA REFORMA DEL ESTADO Y DE LA ADMINISTRACIÓN PÚBLICA, Panamá, 28-31 out.

SILVA, A. C. 2000. "Descentralização em política de ciência e tecnologia". Estudos Avançados, v. 14, n. 39.

TORKOMIAM, A. L. V. 1996. Estrutura de polos tecnológicos. São Carlos: EdUFSCar. 1996.

TRILLING, L. 1979. "Technological elites in France and the United States”. Minerva, v. 17, n. 2.

VESSURI, H. 2008. "O inventamos o erramos": la ciência como idea-fuerza em América Latina. Bernal: Universidad Nacional de Quilmes.

WHITLEY, R. 2006. The intellectual and social organization of the sciences. New York: Oxford University Press. 


\section{ELITES LOCAIS DE CIÊNCIA E TECNOLOGIA NO BRASIL: O CASO DO PARQTEC DE SÃO CARLOS (SP)}

THALES NOVAES DE ANDRADE MAURILIO DE JESUS SILVA FILHO

Resumo: O presente artigo trata do processo recente de consolidação de elites locais de Ciência e Tecnologia no país. Nesse cenário, é possível perceber o aparecimento de agentes relevantes na área científica e tecnológica em nível local. A relação desses agentes com empresas locais, parques tecnológicos e universidades produz novas interações específicas que aqui analisamos, em especial, o caso do ParqTec de São Carlos, São Paulo.

Palavras-chave: Elites; Tecnologia; São Carlos; Campo Científico.

\section{LOCAL ELITES IN SCIENCE \& TECHNOLOGY IN BRAZIL: THE CASE OF PARQTEC IN SÃO CARLOS CITY, SÃO PAULO}

Abstract: The present paper aims to discuss the recent process of consolidation of local elites in the field of Science and Technology in Brazil. In this context, $t$ is noticeable the outcome of various local level agents of $S \mathcal{E} T$ T. The relation of such agents with local firms, technological parks and universities create some new specific interactions that we analyze, specially the case of ParqTec in São Carlos city, São Paulo, Brazil.

Keywords: Elites; Technology; São Carlos; Scientific Field.

Recebido: 20/07/2014 Aprovado: 14/12/2014 